\title{
Periodos históricos y discontinuidades temporales: ensayo de interpretación
}

\author{
Historical periods and temporary discontinuities: \\ an interpretation essay
}

\author{
RENÁN SILVA \\ Universidad del Valle \\ rj.silva33@gmail.com
}

\begin{abstract}
RESUMEN
El periodizar, es decir, poner una fecha, separar dos momentos de un proceso, indicar dos acontecimientos que pueden caracterizarse como "antes» $y$ "después», es una operación corriente, que tiene toda la apariencia de un "gesto natural", repetido por el historiador en cada una de sus investigaciones. Sin embargo, cuando se le interroga con cuidado, la sencilla operación se muestra en toda su complejidad y revela su dificultad. Es sobre ese punto especifico que quiere llamar la atención el presente texto.
\end{abstract}

Palabras clave: historia, periodización, Novick, Foucault, historiografía

\section{ABSTRACT}

Establishing a period, setting a date, or separating two moments of a process are believed to be common operations by which two events can be characterized as "before" and "after". These appear as "simple gestures" repeated by historians in each of their investigations. However, when analyzed carefully, this operation shows all its complexity, revealing its difficulty. This essay aims to draw attention on this issue.

Keywords: history, periodization, Novick, Foucault, historiography 
"... antes que el tiempo se acuñara en días..."

J. L. Borges, El Mar.

[...] De una materia deleznable fui hecho,

De misterioso tiempo

J. L. Borges, Heráclito ${ }^{1}$

Zn las páginas siguientes, se llamará la atención sobre un tema central Een la práctica de la investigación histórica —el tiempo, los cortes históricos y las cronologías - , pero un tema muy poco cultivado por los historiadores, quienes, en general, prefieren dejarlo en manos de filósofos. Esto es problemático, pues estos últimos no tienen un vínculo real con el análisis histórico concreto y, por lo tanto, ningún conocimiento de los retos metodológicos con que se enfrenta un historiador en su trabajo cotidiano o, de manera particular, cuando tiene que construir un relato demostrativo sobre su objeto de estudio, y debe dar cuenta, entonces, de las varias formas de causalidad y de temporalidad que animan los acontecimientos que ha considerado luego de un largo trabajo de archivo.

Para plantear el problema, se hará referencia a los historiadores Peter Novick y Michel Foucault, quienes elaboraron dos perspectivas diferentes del problema de la periodización de los acontecimientos, del tiempo histórico y de las relaciones entre continuidad y discontinuidad de los procesos históricos, punto sobre el que realizan consideraciones explícitas. Al final, se podrá observar que se trata de dos formas posibles de abordar estos problemas. Una, más cómoda, se vincula sobre todo con una forma habitual «no problemática» de considerar estos asuntos, y sostiene que los cortes del tiempo histórico en periodos, etapas, o fases,

${ }^{1}$ La frase pertenece al poema El Mar (Borges 2007, II: 370. Las palabras de Borges sobre Heráclito se encuentran en el poema de ese nombre, incluido en Borges (2007, II: 409. Borges estudió, meditó seriamente e hizo bromas sobre el tema del tiempo y lo mantuvo a lo largo de su vida como una de sus grandes inquietudes. Además, fue claro en afirmar que semejante problema no había encontrado solución: «No sé si al cabo de veinte o treinta siglos hemos avanzado mucho en el problema del tiempo. Yo diría que siempre sentimos esa antigua perplejidad, esa que sintió [...] Heráclito, al que vuelvo siempre: "Nadie baja dos veces al mismo río"” (Borges 2007, IV: 241-251). 
son un recurso para ayudarse en la exposición de los procesos históricos. La otra, de mucha más elaboración intelectual, se caracteriza por una reflexión constante sobre los temas del tiempo en el campo mismo de la investigación histórica, y los vincula a la forma misma que pueden asumir los acontecimientos considerados.

En ningún caso esta corta exposición piensa que las soluciones presentadas por este segundo autor constituyen una solución del problema de la periodización. En realidad, se trata de una gran hipótesis de trabajo, que se mantuvo siempre ligada a procesos de investigación, y no pretendió nunca constituir en una reflexión al margen de la propia consideración histórica de los problemas de la sociedad.

Peter Novick, conocido historiador norteamericano que ha trabajado sobre los intelectuales y las comunidades judías del siglo XX, y quien de manera repetida se interrogó sobre la profesión de historiador y sobre las posibilidades reales del conocimiento histórico — con sus enfoques, sus métodos y sus técnicas - de dar cuenta del tiempo mismo como dimensión constitutiva de los problemas que investigó. Para presentar la reflexión de Novick, se tomará su trabajo Ese noble sueño. La objetividad y la historia profesional norteamericana, en el que de manera explícita abordó el "problema del tiempo» respecto a la evolución de la profesión del historiador en Estados Unidos.

En las palabras iniciales de su libro, refiriéndose a los «trozos» en que ha "partido» $\mathrm{o}$ "distribuido» los años que quiere estudiar, Novick escribe:

La más universal de las «ficciones reguladoras» que los historiadores emplean para poner algún orden en el pasado caótico es la periodización mediante la cual cortamos el hilo continuo del tiempo en longitudes manejables y después hacemos lo que podemos para presentar esas divisiones como si fueran naturales en vez de ideadas. ${ }^{2}$

${ }^{2}$ Novick 1997:28-29. 
Si bien dicha observación tiene una simplicidad engañosa, se dejará de lado la discusión acerca de si el pasado humano es irremediablemente un "pasado caótico», una afirmación que el propio Novick también deja por el camino sin someter a ninguna interrogación especial, lo que recuerda que aun en obras importantes de la historiografía siempre quedan algunas cuerdas sueltas, incluso en relación con puntos centrales de la materia investigada. ${ }^{3}$ Se pondrá atención, en cambio, a la afirmación de Novick - en realidad uno de los supuestos de su trabajo - acerca de que cualquier «orden» que se crea observar en la marcha de los acontecimientos es introducido a posteriori y con algo de arbitrariedad por lo estudiosos, lo que recuerda que las viejas batallas entre «realistas» $\mathrm{y}$ «nominalistas» en análisis social continúan en el escenario de la discusión. Sin embargo, no es objetivo de este artículo sacar ninguna conclusión general sobre este punto que, como es sabido, es objeto de repetidos debates. ${ }^{4}$

Un punto crucial, que en muchas oportunidades es pasado por alto, es el hecho de que la caracterización primera de las llamadas «épocas históricas» — «acontecimientos históricos», «sucesos históricos» $\mathrm{O}$ «momentos históricos», no importa ahora la designación —, un elemento determinante en las formas y contenidos de toda periodización histórica, es, en principio, realizado por las propias sociedades. Se trata de un punto que no encuentra ninguna elaboración en la obra de Novick, quien en su propio trabajo necesariamente tiene que apoyarse en muchas de las formas habituales de designar una época, y que son por lo tanto anteriores a su trabajo, y que dicho autor recibe sin ninguna discusión. Existe,

${ }^{3}$ Luego de la última gran crisis del marxismo, doctrina que sostenía la idea de «leyes» en la historia, parece haberse abandonado todo intento en esa dirección y las nociones de azar, de incertidumbre, de evoluciones fortuitas, y la crítica de toda interpretación determinista, parecen comandar, en forma un tanto implícita, la visión de fondo de los historiadores, sin que el problema se aborde de manera explícita. Es posible, sin embargo, que, pasada la justificada euforia de haberse roto con las formas ingenuas de determinismo que defendía el marxismo, el problema vuelva a plantearse, y se supere la actual consideración de que el problema no vale la pena de ser considerado, como si todo intento de observar el problema de los condicionantes de la evolución histórica de las sociedades humanas, fuera una especie de atentado contra la "eterna libertad humana». ${ }^{4}$ Sobre la antigüedad y la reproducción constante de esas viejas batallas, véase Tosel 2004: 63-72. 
pues, una ausencia en la obra de Novick de alguna reflexión, siquiera mínima, por lo menos, sobre el hecho de qué son las «sociedades», y, de manera más precisa, ciertos grupos sociales — por ejemplo, grupos intelectuales específicos, de distinto nivel y jerarquía social—, los que caracterizan y bautizan esos "cortes de tiempo" que designamos como "periodos históricos», punto notable que pone de presente la relación entre las «representaciones colectivas» que una época produce de sí, y el trabajo de elaboración que sobre ellas realizan los "profesionales de las letras», o simplemente de "la palabra», bien sea para producir procesos de «objetivación distanciada frente a esa primera elaboración», bien sea para dar una forma estilizada a lo que ya se encontraba en el núcleo de la representación social sobre la que se trabaja.

Como se sabe, este fue un punto mencionado de forma insistente en la época del bicentenario de la Revolución francesa, cuando se recordó que la caracterización del pasado inmediato francés como de «Antiguo Régimen", con todas las connotaciones negativas de la expresión, era obra del propio presente, a través de los más activos partícipes del acontecimiento revolucionario. 5 Se trata de un ejemplo particular, aunque de importancia, y de un ejemplo de alcance mucho más general, respecto a un hecho que se encuentra presente en casi todo ejercicio de periodización. ${ }^{6}$

5 Furet 1989: 511-521. El mismo análisis se puede aplicar, con un cubrimiento temporal más amplio, a la idea de Edad Media o de Renacimiento, todas «invenciones» de los críticos de un presente o del intento de restituir el pasado en el presente, bajo otra forma, la «Antigüedad», como en el caso del uso del término "Renacimiento» en una época de grandes cambios sociales, culturales y de sensibilidad en Italia. Para un examen preciso de la historia de los «nombres de las épocas» en la historiografía europea, véase Kalifa 2020. En la obra, se indica que los nombres que utiliza un historiador para designar una época pueden corresponder a veces a los términos con que la época se ha designado a sí misma, o bien pueden corresponder a palabras directamente propuestas por el investigador, aunque sucede con frecuencia que se trata de una combinación que restituye el lenguaje de época y lo transforma por el análisis.

${ }^{6}$ Desde luego que las sociedades humanas sobre las cuales trabajan los arqueólogos, de manera exclusiva, en razón de la ausencia de cualquier clase diferente al que se puede constituir a través de huellas de la cultura material. 
Retomando la observación de Novick, citada líneas arriba, sobre su propia forma de periodizar la historia en los Estados Unidos y su idea de «ficción reguladora», tal como se entiende su afirmación y teniendo en cuenta el contexto en que se produce, da la impresión de tratarse de una indicación que el autor hace al lector acerca de la forma de cómo procederá a lo largo de su obra. De este modo, en función del tema trabajado (la historiografía estadounidense desde finales del siglo XIX hasta los años ochenta del XX y el papel que en ella ha jugado el «ideal de la objetividad»), propone "cortar» los años que quiere estudiar en «bloques» — en conjuntos diferenciados dentro de una unidad - como una forma de orientar al lector. Se trata, entonces, de un factor de su proceso de exposición, pero hay que enfatizar que se trata también de una forma de presentar un elemento de construcción de tiempo histórico, que se encuentra en el centro mismo de su análisis y de sus procesos de trabajo investigativo; es decir, nos encontramos frente a un elemento central desde el punto de vista del método de trabajo del historiador y de sus propias concepciones sobre el tiempo.

En su sencillez engañosa, las palabras de Novick contienen la enunciación implícita de un gran problema de teoría y método - que se traduce de manera directa en la práctica del oficio-, y el autor sale de la dificultad de manera rápida con una "fórmula» muy adecuada para la ocasión, designando el corte histórico temporal en la materia estudiada como una "ficción reguladora». Se trataría de un artificio del que no puede desprenderse ningún investigador en historia, pese a que varíen los criterios que se utilizan para realizar la tarea, y ello aunque pretendiera escribir la «historia de la humanidad desde sus primeros días hasta el presente», en cuyo caso se estaría recurriendo a dos cortes muy claros: los llamados primeros días y el presente; dos cortes, además, muy difíciles, sino imposibles, de establecer. ${ }^{7}$

7 La idea del tiempo como invento humano es una constante en Borges - como lo indica nuestro primer epígrafe-. Este autor dice también en muchas partes de su obra que el tiempo es una ficción que al «final» se desbaratará. Como en "Amorosa anticipación», en donde escribe: «[...] como Dios ha de verte/ desbaratada la ficción del tiempo/ sin el amor /sin mí» (Borges 2007. II: 66); y no deja de señalar que, en todo caso, el tiempo 
Es interesante —en términos superficiales y neutros, y desde varios puntos de vista - que Novick hable de una «ficción reguladora» para caracterizar la operación de periodización, y que diga que es la «más universal de todas las operaciones que ejecuta el historiador». Hay que detenerse en la segunda parte de la expresión: la noción de regulación y de norma regulatoria — utilizada en la ciencia, en la práctica de los deportes, en el análisis económico y en la ciencia política, entre otros campos- se opone a la idea de práctica espontánea, «salvaje», incontrolada. En el terreno del análisis económico, se sabe que la idea de regulación (por ejemplo, «regulación de los mercados») es una idea básica que marxistas e institucionalistas han opuesto a la idea de mercados sin control exterior, que contendrían por sí mismos su principio de equilibrio. En el campo de la actividad de ciencia, los acuerdos parecen ser mayores que en el campo de la teoría económica, y la necesidad de normas de regulación es un punto sobre el que fácilmente se pondrían de acuerdo muchas «escuelas de ciencia» muy diversas en otros puntos; aunque sobre el contenido concreto de esas normas, su verificación a través de determinadas «instituciones del saber» y las formas de su evolución, seguramente existirían discrepancias, e incluso el punto puede llegar a constituir un asunto problemático y un principio de división. ${ }^{8}$

En el uso que hace aquí Novick de la expresión "ficción reguladora», regulación quiere decir norma colectiva de ciencia de carácter social e institucional. Para el historiador, no se trata de una norma arbitraria que resulte ser simplemente una imposición de grupo o un producto del azar o una determinación caprichosa de un grupo de productores de ciencia. No se trata de ninguna manera de una imposición carente de toda razón,

es «materia» difícil de «agarrar» y de conceptualizar, lo que resulta realmente angustioso, porque entonces la propia materia de que estamos hechos resulta un verdadero misterio: «El tiempo es la sustancia de que estoy hecho», escribió muchas veces. Así. por ejemplo: «El tiempo es la sustancia de que estoy hecho. El tiempo es un río que me arrebata, pero yo soy el río; y es un tigre que me destroza, pero yo soy el tigre; es un fuego que me consume, pero yo soy el fuego» (Borges 2007: 181).

${ }^{8}$ Sobre el papel de las normas acordadas en la validación de las obras de ciencia —acuerdo que no descarta los elementos de imposición - véase, Bourdieu 2003, en particular, capítulo II, numerales 2,3 y 4. 
ya que ese tipo de normas y su puesta en práctica obedecen en realidad a formas precisas de racionalidad — desde luego, históricas y discutibles_y bajo ciertos aspectos, resultan una conquista cuando se las sabe emplear de manera razonable y creativa. En este caso particular, Novick quiere acentuar ante todo que se trata de una norma que cumple una función positiva, pues sin esa «ficción reguladora», el trabajo del historiador con el tiempo sería imposible.

Novick enfatiza que las separaciones y cortes que hacen los historiadores cuando periodizan son, en general, recursos cómodos, útiles e imposibles de abandonar. En el fondo, se diría, el tiempo es un continuo, como pensaba Heráclito, una «sustancia» que fluye, y las separaciones que introducimos son puntos de orientación, que se dibujan sobre la propia senda que la memoria humana y que sus «anales» van registrando, aunque de nuevo hay que recordar que el historiador en este punto crea menos de lo que se imagina, y la definición primera de una época, de un periodo, de una «era», la imponen en general ante todo los grupos sociales, sus intelectuales y las instituciones que los orientan, como se ha señalado, y los historiadores juegan casi siempre sobre un hecho creado, para aceptarlo o contradecirlo.

Inquietante puede resultar el uso del término «ficción», que a lo largo de los primeros sesenta o setenta años del siglo XX era una palabra que había encontrado cierta estabilización en cuanto a sus significados en el campo de las ciencias, por diferencia con su significado en el campo de la literatura, particularmente de la novela. Como es sabido, desde hace

9 Las disputas sobre esos términos mantienen su actualidad de una manera que sorprende, y muchas veces se vuelve a su discusión cuando se creía que se trataba de asunto cerrado, dando lugar a discusiones en las que fijar su relación con el presente colectivo parece más difícil, aunque no imposible. Para ofrecer solo un ejemplo, recordemos que Jacques Le Goff — y en eso lo acompañaron otros medievalistas — sostuvo hasta el final de su vida que, bajo ciertos aspectos, la Edad Media llegaba hasta el mismísimo siglo XIX; véase Le Goff 2008. Hay que señalar, para ser precisos, que Le Goff no se encontraba tratando de hacer «historia experimental», al afirmar que la Edad Media llegaba por lo menos hasta 1800, sino que se encontraba firmemente convencido de que muchas de las instituciones y formas sociales medievales mantenían su funcionamiento en la sociedad, más allá de cualquier analogía, y que constituían además un elemento perdurable de civilización. 
más o menos medio siglo, por circunstancias de la coyuntura intelectual, la palabra y su significado se volvieron asunto de candentes debates y en punto de deslinde entre escuelas históricas. ${ }^{10}$ Un debate en el que, sin mucho orden ni concierto y con demasiada acritud y escasa definición de los términos utilizados, se ha polemizado de manera interminable. ${ }^{11}$ La bibliografía sobre el asunto es enorme y, al parecer, viene de todas las regiones del mundo, y resulta imposible referirse a ella de una forma que no sea unilateral, por lo que resulta mejor seguir de largo sobre ese punto. Se debe recordar, sin embargo, que un partícipe activo y constante en la discusión ha sido Carlo Ginzburg — un historiador de presencia familiar en la discusión de los historiadores latinoamericanos-, un testigo comprometido en el debate con una posición muy definida, pero un testigo inteligente, capaz de decir cosas realmente importantes sobre el problema. De modo que quien tenga tiempo y se interese por el tema puede dirigirse, por ejemplo, a algunos de sus muchos textos al respecto, o incluso contentarse con algunos de los que ofrece Ginzburg en El hilo $y$ las huellas, donde precisa muchas de sus posiciones sobre el tema. ${ }^{12}$

Hay que recordar de todas maneras, para ser justos y evitar equívocos, que en Peter Novick este recurso de la convención puramente nominal — el tiempo es una continuidad, un fluir diría Borges — no significa que comparta las ideas del escritor argentino al respecto. La idea de que los cortes que hacemos en «el tiempo» tiene mucho de artificio encuentra como principal justificación en Novick una razón de método y de oficio. Se trata de un artificio para poder hacer mejor nuestro trabajo, una vieja

${ }^{10}$ Ginzburg 2000 y Silva 2004.

${ }^{11}$ Este debate no hay que lamentarlo. Se debe más bien recordar el papel positivo que en el campo del conocimiento ha cumplido la controversia. Solo hay que aspirar a que los términos básicos de la polémica se encuentren bien definidos, y que los oponentes actúen con buena fe, y olviden la expresión «le repito que tengo razón», en realidad una expresión que carece de todo sentido en el campo de la ciencia. Citemos, solo por comodidad, sin ningún interés doctrinario, lo que el joven Marx observaba sobre este asunto de «tener» la verdad o la razón en un problema de conocimiento: «La verdad es universal, ella no me pertenece a mí, sino que pertenece a todos [...] "Mi propiedad" es la forma, es mi individualidad histórica. Lstyle c'est l'homme» (Marx 2008).

${ }^{12}$ Ginzburg 2010. 
estrategia historiográfica que en cierta manera pertenece a todos y a nadie, y que se encuentra en todas las historiografías de manera al parecer universal, sin importar lo antiguo de la tradición — letrada o no- de que hablemos. Sería, pues, una tradición respetable y venerable en el oficio, pero que cuando se examina con detalle podría revelar problemas dignos de consideración, no solo respecto de los «cortes» particulares que se pueden hacer al considerar un problema determinado en una investigación concreta, sino respecto de la propia operación de conocimiento que se encuentra detrás de la operación práctica que realizamos, una donde nos apoyamos muchas veces de manera opaca e indiscutida, aunque en verdad realizamos una operación intelectual compleja, con poca conciencia de lo que hacemos.

\section{II}

Se puede tratar de ir un poco más allá de las palabras de Novick, manteniendo el problema que plantea, y buscando otras posibilidades de abordar la llamada "ficción reguladora», una operación a la que de todas maneras podemos reconocer su universalidad, no en cuanto a su contenido y ni siquiera en cuanto a su forma, sino en su carácter general de recurso para enfrentar el "río del tiempo», una operación social y cotidiana, que desde luego no se limita tan solo al trabajo del historiador profesional especializado. ${ }^{13}$ Se trata, por tanto, de una operación que es una constante de la vida social, y que en el campo más restringido de

${ }^{13}$ De este modo, en el «pasado reciente» de lo que se designa como «América precolombina» hay pruebas conocidas de la existencia de formas de conservación de la memoria, más allá del simple mito localizado que tiende a reproducirse siempre igual a sí mismo. Así sucedía, por ejemplo, entre los «antiguos mexicanos», quienes, a pesar de la carencia de escritura alfabética, pero con el recurso a los pictogramas y a formas muy eficaces de memoria, preparaban en las comunidades a algunos de sus miembros como agentes activos de la conservación de la memoria. Véase Gruzinski 1991, que cita varios testimonios al respecto, tal como los consignaron los cronistas tempranos de Nueva España. Lo mismo se sabe de muchas sociedades del África, que también organizaban «lugares de memoria» de manera al tiempo eficaz e informal. Véase, Goody 1998, especialmente capítulos IV, VI y VII. 
lo que designamos como historiografía puede rastrearse desde las más antiguas - las que tuvieron su existencia en el interior de las religiones y, posteriormente, en las formas iniciales de sacralización de las dinastías e imperios - hasta los «regímenes históricos» que se pueden observar entre los siglos XVI al XX en Europa y América, ${ }^{14}$ con sus ideas distintivas de un saber histórico soportado por una corporación de historiadores, con un cuadro documental y archivístico organizado, y con procesos de enseńanza normalizada, lo que en cierta manera remata en la idea de "historia ciencia», en el siglo XX. ${ }^{15}$

Se advierte, además, porque tiene que ver con nuestro problema central, que esta idea de una "historia ciencia» ha sido muy combatida desde finales del siglo XX, y en las dos primeras décadas del siglo XXI a veces se ha visto "contra las cuerdas» y casi al borde del colapso bajo los ataques de fuerzas dispares, que expresan una deseo y una necesidad legítimas de «memoria» y de participación en la vida social, fuerzas que a su vez deberán enfrentar el reto de responder a preguntas difíciles como «¿Y entonces qué tipo de historia?». Este ejercicio debe realizarse si sencillamente no se quiere dejar en el olvido las conquistas culturales que el saber histórico ha realizado desde la antigüedad hasta el presente, única forma de evitar desembocar en la mala idea de que cualquier relato del pasado es válido, con independencia de sus formas de producción y verificación, por lo menos si se quiere mantener vigente la aspiración de que el análisis histórico sea una forma de conocimiento controlado en sus operaciones, basado en argumentaciones y pruebas.

Este es un asunto abierto a la discusión y un gran objeto de disputa, y aún no parece claro cuáles serán las formas distintivas del conocimiento historiográfico que caracterizarán al siglo XXI. En todo caso,

${ }^{14}$ La llamada «Historiografía colonial» de América hispana — de manera básica, los cronistas, sobre todo aquellos de las órdenes religiosas - constituye un universo de una riqueza historiográfica que parece no ha tenido hasta el presente la atención que merece, y cuyo análisis remite a la cultura histórica europea anterior al positivismo rankeano, y en particular, a la forma de escribir la historia en medios eclesiásticos. La riqueza historiográfica de esos siglos XVI-XVII merecería una reflexión de tanta erudición como la que ha desplegado Grafton (2007).

${ }^{15}$ Iggers 2012. 
los asuntos — pasados, presentes y futuros - acerca de la forma como los historiadores - o quien se encargue en una sociedad de esa forma especializada de memoria - realizan sus cortes en el tiempo para organizar sus narraciones son materia compleja, sobre los que siempre vale la pena reflexionar. ${ }^{16}$

Este texto se limita a algo mucho más acotado y modesto, pero que puede ser de utilidad para quienes abordan la profesión histórica como la práctica de un oficio, razón por la cual no separan en su trabajo teorías de métodos, y de artesanía intelectual, y saben que para el historiador de oficio una forma privilegiada de lectura de las obras de los historiadores es la de interrogarlos por la forma como piensan sus problemas de enfoque, la manera como construyen sus objetos, y, en este caso, de manera particular la forma como abordan los problemas teóricos y prácticos de la periodización. En otras palabras, de manera consciente se deja de lado toda referencia a los trabajos de "filosofía de la historia» tal como esta disciplina funciona de manera habitual, es decir, como una modalidad de especulación poco o nada conectada con las formas concretas y efectivas del trabajo de los historiadores, especie de discurso «metahistórico», detrás del cual se encuentra muchas veces el propósito de señalar, y en cierta manera imponer, las reglas de manejo del tiempo histórico y la construcción histórica, adoptando un punto de vista exterior a la práctica real de la disciplina histórica. ${ }^{17}$

${ }^{16}$ En los ambientes intelectuales postmodernos, se ha propuesto en varias oportunidades, sobre todo entre antropólogos, una crítica importante de las concepciones puramente lineales del tiempo histórico con las que trabaja, en general, la historiografía que fue dominante en buena parte del siglo XX, por lo menos en el caso del positivismo renovado y del marxismo, dos de sus corrientes más sobresalientes. La crítica, que puede ser justa en muchos puntos, remite casi siempre a sociedades que en sus mitos y relatos de fundación exhiben otras concepciones del tiempo, diferentes a las de las sociedades del orden de la civilización judeo-cristiana. Sin embargo, esta crítica, que se puede calificar de justa desde el punto de vista del conocimiento histórico, y que puede ser una crítica del etnocentrismo, deja de lado los aspectos positivos, de conocimiento y civilización, que, para la ciencia, para el saber histórico y para la vida social ha significado el llamado tiempo lineal.

${ }^{17}$ Véase, por ejemplo, Caianiello (2009: 111-139). Un texto de una gran erudición, pero no menos una prueba de un tipo de conocimiento encerrado en el «textualismo», 
Para tratar de presentar de la manera más clara posible los asuntos complejos abordados, se tomará un camino sencillo — menos sencillo de lo que parece a primera vista - : presentar la forma como el problema se planteó e intentó resolverse en la obra de un autor preciso: Michel Foucault, un autor que no dejado de tener un impacto importante en las ciencias sociales de América Latina, aunque parece que leído de una forma no muy productiva en relación con los interrogantes que se plantean.

Corresponde hacer un corto recorrido por algunas de las obras de análisis histórico de uno de los pensadores más conocidos e influyentes en el medio cultural e intelectual de la segunda mitad del siglo XX, Michel Foucault. Se señalará, a manera de síntesis, lo que constituye la idea básica de esta sección del artículo — para pasar luego a la demostración requerida - : en Foucault hay una noción diferente de la que se citó anteriormente de Novick. Pareciera que hay una idea menos "cómoda" y más productiva en términos de investigación, una idea más compleja del problema de las periodizaciones, una idea que va más allá de considerar la periodización como simple recurso puramente instrumental. Esa idea es importante no solo para el trabajo del historiador, sino también para la lectura de la obra de Foucault, sobre todo si nos referimos a sus grandes trabajos desde el punto de vista estricto de la disciplina histórica, pues, como en el caso de la obra de cualquier autor importante, hay en la obra de este pensador variedad de tratamientos de los problemas, modificaciones de puntos de vista, rectificaciones, nuevos puntos de partida, etc.; en otras palabras, no hay un solo Foucault que sea idéntico a sí mismo a lo largo de su vida como autor. ${ }^{18}$

sin mayor utilidad fuera de los límites de su propio comentario sobre el problema que se intenta examinar.

${ }^{18}$ Parece que el tratamiento de los problemas depende en Foucault de manera exagerada de los auditorios, ante los cuales presentaba sus problemas, lo mismo que de lo específico de la relación pedagógica en que se encuentra en cada caso - como profesor en Túnez o como conferencista en el Brasil o como activista en ruidosas asambleas estudiantiles 
La idea que se encuentra, entonces, es que, —más allá del recurso nominal, al que también acude en ciertas oportunidades, por ejemplo, cuando señala un hito cronológico destacado-, el trabajo del historiador puede establecer, en ciertas oportunidades, en el estudio de un problema determinado, fenómenos de discontinuidad temporal: procesos rotos, desaparecidos, suspendidos en el tiempo y sin nuevas continuidades. Lo mismo sucedería para procesos enteramente nuevos: «nacimientos», invenciones, creaciones que son algo más que recreaciones o cambios de traje, en fin. Lo que puede designarse como «rupturas», fenómenos de discontinuidad que permiten al tiempo potenciar la originalidad de ciertas situaciones históricas, enriquecer los procedimientos y las nociones habituales de periodización con que trabajan los historiadores, y problematizar la representación del tiempo como un «continuo", abriendo de hecho nuevas vías para explicar la aparición del acontecimiento disruptor, de lo «nuevo», de configuraciones históricas antes inexistentes —uno de los problemas básicos de lo que habitualmente se designa como cambio social_- una reconsideración que incluso puede ofrecer nuevas bases para enfrentar el problema de los «orígenes», sin necesidad de volver a las mitologías que al respecto han sido criticadas de vieja data por los historiadores. ${ }^{19}$ Son ideas renovadoras que tuvieron cierta permanencia en la obra de Foucault y a las que dio a veces una expresión muy concreta, por ejemplo, en los textos que ponen de presente su paso de una concepción arqueológica en sus análisis, a lo que designó como genealogía. ${ }^{20}$

Lo que ocurría, se repetía de manera insistente en los trabajos de Foucault y lo que la Historia de las ciencias «a la francesa» enseñaba

en California, o aun como profesor en el Colegio de Francia-. Véase sobre este punto Foucault (2001: 1707 y 1735). Estos dos volúmenes son muy reveladores de las evoluciones del pensamiento de Foucault y de la importancia que en la exposición de algunos de sus puntos de vista tuvieron los auditorios y los medios de comunicación.

${ }^{19}$ Como se sabe, la crítica del «mito de los orígenes» tiene una formulación muy precisa en varios textos de Marc Bloch, entre ellos en su importante Apología de la historia o el oficio de historiador (Bloch, 1993). Este autor recoge, desde luego, una idea que un conjunto de historiadores venía poniendo en marcha desde principios del siglo XX.

${ }^{20}$ La mejor exposición del problema, bajo una forma de síntesis, se encuentra en Foucault 1988. 
en esos años, ${ }^{21}$ es que una especie de fantasma había acompañado por mucho tiempo el trabajo de los historiadores. Un fantasma que había operado como un obstáculo para abrirle camino a la idea de discontinuidad: se trataba de la idea de antecedentes, como cuando Max Weber en su Historia económica general, para ofrecer un ejemplo significativo, ve capitalismo en la antigüedad porque observa funcionamiento de mercado o de dinero, o incluso formas de trabajo asalariado. ${ }^{22}$ "Antecedentes» y «precursores» — ¡otro obstáculo para pensar el problema!_, dos falsos amigos heredados de la educación escolar, del aprendizaje «seminconsciente» de la «historia relato», un recurso propiamente literario muy eficaz con el que se narran los cuentos y las fábulas a los niños, pero que, cumpliendo la función de insidioso "pasajero clandestino", se había colado en la llamada "historia problema», en donde muchas veces se confundía la «larga duración» con una visión de continuidad «sin sobresaltos». ${ }^{23}$

La formulación resultaba de gran complejidad, y sus efectos intelectuales no fueron los mejores, ya que lo que era en principio en Foucault una hipótesis para el trabajo pronto se convirtió en un instrumento polémico que se utilizó con demasiada frecuencia en los combates universitarios como arma contra el oponente, y el propio filósofo tuvo que referirse varias veces al tema y advertir que no se trataba de ser "discontinuista» a ultranza, o de no serlo, y debió rechazar los elogios gritones a la «discontinuidad» en los medios intelectuales que le eran favorables. Estos grupos se revelaron como conformados por apresurados discípulos a quienes el «jefe de filas» debió recordarles que, primero, la existencia de procesos

${ }^{21}$ Véase Canguilhem 1970, de manera especial, «L'objet de l'histoire des sciences», p. 9 y ss. Para conocer los empeños de historización de las ciencias y el conocimiento en Francia en esos años, bajo el impuso de estudiosos como Bachelard, Koyré, Canguilhem, véase Castelli Gattinara 1998. La inscripción temprana de Foucault en esa tradición se encuentra presente en el estudio de Macherey 2011. Véase, por ejemplo, «De Canguilheim a Canguilheim pasando por Foucault». Macherey habla —en un ensayo de 1990 — de una comunidad de concepciones, «[lo] que no excluye la diferencia y hasta la oposición de los puntos de vista» (Macherey 2011: 122).

${ }^{22}$ Weber 1942.

${ }^{23}$ La expresión "pasajero clandestino» es de Passeron (2011). 
discontinuos debería demostrarse y no simplemente predicarse, y que, segundo, podía ocurrir que muchos o algunos de los elementos que se designan como «antecedentes» adquirieran un lugar y una función en una nueva estructura, y que por lo tanto deberían ser redefinidos en el interior de la nueva constelación —o configuración — de la que formaban parte, y no podían ser simplemente rechazados como producto de un error de análisis, lo que suponía una operación compleja en el estudio de los procesos históricos. Finalmente, señaló en varias oportunidades Foucault, que la historia de la sociedad y de las ideas lo continuo y lo discontinuo no eran dos realidades que simplemente se opusieran, sino dos tipos de historicidades que se combinaban de formas que solo el análisis histórico concreto, bien documentado, podía determinar.

La lectura de los textos foucaultianos bajo el ángulo del problema de la periodización y la discontinuidad muestra, además, que su idea daba lugar a un doble contenido. De una parte, el resultado al que llegaba era el producto de una investigación precisa sobre un tema determinado, con marcadores espacio-temporales bien definidos y circunscritos, que aparecen recogidos en el título mismo de algunas de sus obras. De otra parte, Foucault convertía el instrumento conceptual en un elemento de la forma de exposición, al tiempo que lograba integrarlo como un recurso de estilo. Un ejemplo preciso de las afirmaciones anteriores se encuentra ya presente en su primera gran obra, titulada con toda exactitud Historia de la locura en la época clásica, ${ }^{24}$ con lo que no dejaba dudas en el posible lector. Se trataba de una "historia», de la historia de un "objeto», y de una historia localizada en una «época» determinada: la llamada «época clásica», según las convenciones académicas de la historiografía europea.

La lectura de los textos permitía observar también que la forma de periodizar — es decir, de efectuar «cortes» en la "materia» con la que trabaja - podía cumplir funciones de hipótesis. Como, por ejemplo, cuando acude, para orientar sus trabajos, a ciertos acontecimientos de la Revolución francesa, es decir, que el «corte utilizado» — la ficción reguladora de Novick — podía convertirse en un instrumento para interrogar

${ }^{24}$ Foucault 1976. 
a la propia Revolución francesa desde el punto de vista de su novedad y su actualidad. Incluso, por esta vía se abría paso a la novedosa idea de que, desde el punto de vista propiamente experimental, una periodización podía convertirse en una "técnica de ruptura» con las prenociones, en la medida en que operaba como un instrumento que permitía inscribir ciertos eventos en un orden temporal, o excluirlos de ese orden, y sacar conclusiones de la opción tomada. ${ }^{25}$

Del examen cuidadoso de las grandes obras de Foucault en la primera época de su producción en el terreno estricto de la investigación histórica, resulta claro, entonces, que el «historiador-filósofo» no especulaba sobre el tema de la periodización, sino que trataba de hacer funcionar su enfoque en sus trabajos, o más exactamente, que sus proposiciones dependían de su propia experiencia de trabajo como historiador, y que la introducción de nociones como la de «discontinuidad» resultaba de múltiple utilidad, pues más allá de su uso en esta o aquella investigación, permitía discutir sobre problemas generales de la práctica del oficio, y sobre uno de sus conceptos mayores: el tiempo.

Es posible hacer un breve repaso del asunto en las obras iniciales de Foucault, para aclarar un poco más la idea y el argumento que de ahí se desprende. Por ejemplo, cuando se lee con cuidado la antes citada Historia de la locura, se nota enseguida que el procedimiento de exposición se encuentra gobernado por una estrategia comparativa, muy bien documentada, que le permite diferenciar dos momentos precisos en la identificación y el "tratamiento de la locura»: aquel momento inicial de la exposición que designa el autor como «Stultifera Navis», esas páginas que describen el procedimiento de «embarcar la locura en una nave» y poner a los locos a navegar sin destino por el mar, pues la sociedad

${ }^{25}$ Renglones arriba, en el interior de una cita, se menciona la expresión «historia experimental», en parte para designar esta idea de utilizar las periodizaciones como forma de probar instrumentos conceptuales _ por ejemplo, la noción de discontinuidad o la noción de «época histórica»—. Ese es uno de los sentidos que tiene la expresión en la utilización que de ella se hace, pero no es su único sentido. El recurso al «anacronismo controlado» es otra de las facetas de esa «historia experimental». Al respecto de usos sabios del anacronismo, puede verse Didi-Huberman 2008. Sobre el tema de la «historia experimental», véase Boureau y Milo 1991. Véase también Lepetit 1999. 
no tenía un lugar para los locos, los incorregibles, los desviados de todo orden. Y, luego, el segundo capítulo, el famoso «Gran encierro», que pronto conducirá a comprender los dispositivos particulares, producto de condiciones y circunstancias específicas, que producirán las primeras formas de "nacimiento del asilo moderno", y por ese camino de la locura, como entidad diferente y nueva, definida por un saber de ciencia y un tipo particular de control social. ${ }^{26}$

Es claro que el asilo de locos, bajo su forma nueva, no existía con anterioridad. Es un tipo de institución que puede tener semejanzas y antecedentes con algunas prácticas anteriores de encierro o de aislamiento, pero que en rigor constituye una nueva realidad social e institucional, con independencia de algunos de los «modelos» de encierro anteriores, con los que ya se había experimentado. Y es esa nueva realidad la que Foucault constituirá en criterio de periodización —un elemento nuevo que introduce una «discontinuidad»—, un hecho que es al mismo tiempo una hipótesis de trabajo y un resultado de investigación, y que se utiliza como elemento formal de exposición, de una exposición que hace uso de una perspectiva comparativa para diferenciar dos «figuras», dos «modalidades», o dicho de forma menos retórica, dos tipos de instituciones, o más exactamente una, el nuevo asilo, construida a partir del abandono de un conjunto de prácticas dispersas que se encontraban «regadas», superpuestas, indiferenciadas a lo largo de la sociedad. De manera concreta, en la Iglesia y las instituciones de caridad, en la familia,

${ }^{26}$ El final del siglo XX conoció la reaparición de cierta forma de la nave de los locos, cuando Fidel Castro — quien desde luego no había leído a Michel Foucault - autorizó a un grupo de cubanos opositores, que habían ocupado la embajada del Perú en Cuba, a marchar libremente desde un puerto vecino, y les sumó como acompañantes a delincuentes comunes encarcelados, algunos presos políticos de oposición, intelectuales disidentes, bohemia urbana, homosexuales, jóvenes drogadictos y en general un gran grupo de «desviados sociales» que no querían vivir más bajo régimen comunista, y que marcharon para E.E. U.U. en barcos que arrancaron del Puerto de El Mariel hacia Miami, entre mediados de abril y fines de octubre de 1980 — en total, fueron unas 125000 personas - En uno de esos barcos, partió el gran escritor cubano, disidente y homosexual, Reynaldo Arenas. En Scarface de Martín Scorsese, se recogen algunos aspectos de estos terribles eventos, y la trayectoria delincuencial de muchos de los «marielitos», ya en EE. UU. 
en formas de asistencia que dependían de todos y de nadie, que poco se distinguían de las formas tradicionales de asistencia a los pobres en muchas partes de Europa, y que eran uno de los instrumentos de «control leve» de las poblaciones, pero que ahora irán a diferenciarse a través de una red institucional de gran originalidad, matriz de saberes que hasta el presente nos acompañan y no dejan de ampliar su influencia, como la psiquiatría y multiplicadas formas de «terapia mental». Verdaderas novedades, en el sentido preciso de la palabra, en el orden del poder y el saber. Creación de una nueva institución que tiene condicionantes que van desde el orden material hasta el orden del intelectual, incluyendo, claro, lo que ya se designaba como ciencia, pero que no menos comprometen al propio conocimiento filosófico, pues sin el trabajo de Descartes sobre la razón y la construcción de una oposición llamada a perdurar, entre razón y sinrazón, no hubiera sido posible la construcción de la nueva noción de locura, y todo lo que de allí se derivó para la ciencia, para una nueva idea de lo normal, y para la creación de instituciones de control y «normalización». ${ }^{27}$

En ese conjunto de prácticas que se hacen y rehacen, una nueva realidad, el asilo, suprime otra forma de hacer el «viaje de los locos», travesía marina sin término que cambia por el encierro en un nuevo lugar diferenciado en un campo institucional en construcción. El resultado, en términos historiográficos y de análisis, es una renovadora obra de historia que pasa por encima de las distinciones habituales del género histórico, que innova en el terreno del enfoque, del método y de los procedimientos documentales, y propone un acercamiento al problema que podía ser utilizado en el estudio de muchas otras enfermedades contagiosas (como la viruela, una plaga que mataba miles de seres humanos, hasta la aparición de la vacuna; o la lepra, productora permanente de sufrimientos personales y familiares y que hoy puede considerarse como un «asunto de dermatología» que no exige el aislamiento, aunque el fantasma que la ronda continúa). En fin, una obra que hubiera podido resultar importante para la formación de jóvenes historiadores si entre

${ }^{27}$ Foucault 1967. 
ella y sus posibles lectores en la universidad no se hubiera interpuesto todo un batallón docente que desvirtuó el contenido, sentido y dirección de la obra, y la convirtió en un pesado ejercicio de falsa especulación filosófica y en el objeto de las más triviales piruetas derridianas, cuando se trataba ante todo de una brillante lección de historia social y de nueva historia institucional. ${ }^{28}$

Se puede examinar, también de manera esquemática y solo para indicar al lector a dónde dirigirse en caso en que se interese por la lectura de este tipo de obras — por fortuna, hoy fuera de toda moda-, como El nacimiento de la clinica ${ }^{29}$ una especie de breve introducción analítica a la historia de la institución hospitalaria y a la práctica moderna de la clínica, subtitulada "Una arqueología de la mirada médica», un subtítulo exacto, pero que arrastró muchos equívocos fenomenológicos, y en donde desde los renglones iniciales del importante prefacio que se escribió para la obra Foucault, se indica que se trata de diferenciar por comparación, dos maneras de conceptualizar la enfermedad, el paciente, y el campo institucional que los acoge o rechaza: «Hacia mediados del siglo XVIII, escribe Foucault, Pomme cuidó y curó a una histérica haciéndola tomar "baños de diez a doce horas diarias, durante diez meses completos"»; para agregar en el siguiente párrafo «Y he aquí cómo, menos de cien años más tarde, un médico percibió una lesión anatómica del encéfalo y de sus envolturas [...]», y señala treinta líneas adelante «Entre el texto de Pomme que llevaba a su forma última los viejos mitos de la patología nerviosa, y el de Bayle que describía, para un tiempo del cual no hemos salido aún, las lesiones encefálicas de la parálisis general, la diferencia es ínfima y total». ${ }^{30}$ A continuación, se explicará el significado de las últimas palabras que citadas y se desplegará enseguida crítica precisas

${ }^{28}$ Véase Foucault 1967: «Apéndices» y 328 y ss., para constatar las observaciones de Foucault sobre la crítica derridiana de la locura, y en general para la crítica del «textualismo postmoderno" y de la ausencia en Derrida de una perspectiva histórica que le hubiera permitido entender de otra manera el «cogito cartesiano» y la propia ob.ra que intentaba criticar.

${ }^{29}$ Foucault 1966.

${ }^{30}$ Ib.: $9-22$. 
sobre la forma como se escribe de manera tradicional la historia de las ideas, avanzando en la fundamentación de lo que pronto se sistematizará bajo el nombre de «método arqueológico».

En El nacimiento de la clínica, hay otros puntos más que subrayar, relacionados con los asuntos de la periodización que realizan los historiadores. El primero de ellos tiene que ver con la manera como Foucault constituye a la Revolución francesa y a sus reformas en el campo de los hospitales, en un hecho que permite afirmar una discontinuidad precisa, impartiendo de paso una lección sobre cómo se analiza un conjunto de reformas en el terreno institucional, ${ }^{31}$ pero sin que ese punto referencial — la Revolución_, lo sea ad hoc, como se hace en la historiografía tradicional hasta el presente. Al contrario, despliega una sucinta pero precisa demostración acerca de cómo se construye en el análisis histórico el tramado de relaciones entre series de acontecimientos de diverso orden, por fuera de toda teleología o consideración determinista del elemento que funcionaría como supuesta "última instancia», una idea de la que Foucault se desentiende sin mayores polémicas, al poner en marcha un «dispositivo» que introduce lo que llamaríamos «formas de multicausalidad», que comprometen procesos de diverso orden y de diferente temporalidad en la formación de un campo nuevo.

El segundo punto tiene que ver con la complejidad del análisis, porque los elementos de la discontinuidad no son simplemente deducidos de la legislación sobre hospitales que produjo la Revolución, sino que se despliegan en varias dimensiones, como, en primer lugar, la del discurso presente en el prefacio de la obra, y luego en los eventos que se relacionan con los sujetos del saber y de la institución, y con la llamada «mirada médica». Es decir, expresado de manera sintética, que los criterios que permiten construir la discontinuidad y la periodización no dependen de un solo orden de elementos, sino de una serie de acontecimientos que se relacionan con hechos de sociedad — políticos, económicos, administrativos, de saber, ideológicos_-, y cada uno de ellos no dependiente de una sola forma temporal en sus evoluciones y

31 Ib. Véase en particular el capítulo V: «La lección de los hospitales». 
transformaciones propias. El esquema, en principio, puede reducirse al universo de interacciones entre las prácticas, las instituciones, los sujetos, y los discursos, cuatro elementos sobre los que Foucault fijó casi siempre su atención. Pero cada uno de tales elementos se desdobla y multiplica desde el punto de su genealogía y formación en muchos otros elementos, de tal manera que al final el acontecimiento disruptor, cuando se hace visible, condensa procesos y lógicas que vienen de campos diversos (con temporalidades diversas), dando lugar a una compleja historia social, que inscribe sus evoluciones en un conjunto muy disímil de prácticas y de acontecimientos.

De manera similar sucede con Vigilar y Castigar, subtitulada Nacimiento de la prisión, ${ }^{32}$ una obra que por muchos aspectos merecería un tratamiento aparte, porque concreta una nueva dirección de su trabajo, que Foucault llamará «genealógica», pero que podemos dejar de lado ahora, dado lo acotado de nuestro propósito aquí. Una obra que en cuanto a discontinuidades, manera de periodizar y forma de exposición, mantiene las mismas características con relación a los usos del método comparativo - del suplicio físico directo del cuerpo hacia nuevas formas de encierro y de tratamiento disciplinario-, y que es un paso nuevo desde el punto de vista de la riqueza de la escritura, lo que recuerda la relación que existe en Foucault entre documentos de investigación, forma de exposición y estilo literario.

Como sabemos, el libro arranca con las escenas terribles del suplicio de Damiens en 1755 , en un capítulo que se titula precisamente «El cuerpo de los condenados». La segunda parte presenta la figura del castigo, al tiempo que se describe con todo detalle el surgimiento de los procedimientos que especifican esa forma nueva de castigo que conserva la vida; en tanto que en la tercera parte, la obra va largo sobre la nueva realidad histórica de la disciplina, que será en los años siguientes uno de los dispositivos que más estudiará, en relación con otros problemas, con otros periodos y otras instituciones. El libro se cierra con el examen de la nueva realidad institucional de la prisión, en cuya moderna creación va a

32 Foucault 1976. 
ser grande el papel de la Revolución, como discurso y como legislación, y cuya arquitectura central presenta a través de la obra de Bentham. ${ }^{33}$

No hay dudas de que el mismo método comparativo y las mismas formas de establecer la relación entre periodos y discontinuidades, y un estilo de construir la forma de exposición, se encuentra en Las palabras $y$ las cosas, ${ }^{34}$ aunque parezcan muy justas las críticas a cierto esquematismo reductor que se encuentra presente en el tratamiento del material histórico en esa obra, lo mismo que la crítica a la noción de «episteme» (por lo demás, muy parecida a la idea de Thomas Kuhn de "paradigma»). Esta resultaba en una fuerte simplificación de los procesos históricos, por fuera de que, en el libro, en este mucho más que en los demás, es notorio el sacrificio de las «comunidades de enunciación» y de los «sujetos enunciadores» en función del estudio abstracto del «enunciado». ${ }^{35}$ Pero, en fin, este es un problema de análisis histórico de gran entidad, y por lo tanto de gran dificultad, y debemos dejarlo de lado en esta oportunidad. Por su parte, La arqueología del saber, ${ }^{36}$ el gran "tratado de método" del Foucault arqueólogo, sintetiza todos sus trabajos importantes hasta esa fecha, desde el punto del análisis del lenguaje — los enunciados, los «actos de habla» y el discurso- - al tiempo que señala con claridad las limitaciones que el propio autor reconoce a su enfoque de esos ańos. Así, por ejemplo, cuando se pregunta en la introducción de la obra sobre

33 Vigilar y castigar fue una de las obras más «gustadoras» de Foucault y su título se volvió un atractivo para los nuevos jóvenes universitarios — realmente muy jóvenes ya en estos años-, quienes no parecen haber necesitado leerla para hacerla un ícono representativo de sus aspiraciones libertarias. Jóvenes que descreían de toda «vigilancia y castigo», y denunciaban toda forma de control social como una limitación a su libertad. Sobre la obra y su relación con el "clima antiautoritario de esos años», véase Bourdieu 1999, en donde con muy buen humor se muestra la forma como las condiciones de circulación condicionan la lectura de una obra. No parece que el contexto de circulación de la obra en los países de América Latina haya sido muy diferente, y efectivamente muchos jóvenes la hicieron su blasón, aunque pronto desalojado por la «modernidad líquida», y luego por otras novedades editoriales, en medio de un mercado que se renueva a gran velocidad.

34 Foucault 1968.

35 Véase De Certeau 1987, en particular los capítulos I, II y III.

36 Foucault 1970. 
las relaciones entre sus análisis y la historia política y social, y responde que esa relación «entre el discurso como estrategia» y la «formación social», "permanece por ahora en el taller de su elaboración». A pesar de su lenguaje, muy rico y de alto contenido literario, aunque a veces envuelto en la provocación y en el juego con el lector o en las complicidades secretas con sus amigos de ese entonces, es una obra menos compleja de entender y asimilar que lo que piensan aquellos que la han declarado «muy difícil», y que la han convertido en un tabú, en cambio de limitarse a reconocer que no la entienden. No obstante, en esa obra se encuentra muy bien presentado el problema de los cortes históricos y de las formas de periodizar, lo mismo que el significado del recurso al tiempo largo o al tiempo corto en el análisis de un problema histórico determinado, indicando Foucault con exactitud cuál es la importancia de la llamada Escuela de los Anales en el campo de la historia social y económica, y cuáles son las tareas nuevas que plantea el análisis histórico de los «sistemas de pensamiento» si se quiere abandonar el campo tradicional de la historia de las ideas.

Por lo demás, en la Arqueología del saber, y de manera particular en la introducción, se encuentra un elemento que apenas ha sido visto por los comentaristas de Foucault: el hecho de que en su trabajo una noción puede ser, al mismo tiempo, como en el caso de la noción de discontinuidad, un instrumento para el trabajo — le ayuda al investigador en su observación de los hechos históricos que somete a interrogación-y una noción, que se asume como una hipótesis, y que, por lo tanto, debe ella misma ser sometida a interrogación. Por fuera, en la obra no hay separación entre el análisis propiamente histórico y el análisis epistemológico sobre los instrumentos con los que interroga las formas de practicar el análisis histórico y la propia vida de las sociedades.

Si tuviéramos que sintetizar la forma como opera en esas obras el «dispositivo» de periodización en Foucault, podríamos decir, de manera esquemática, que se encuentra presente en el propio método de exposición y en el uso que hace del método comparativo, y que es la manera más visibles de manifestación en su trabajo la noción de discontinuidad, una idea que es un resultado del propio trabajo de investigación, pero 
que al mismo tiempo cumple el papel de hipótesis de trabajo y de técnica de ruptura frente a las visiones tradicionales de pensar un problema. Es decir, el dispositivo se utiliza también como una manera de proponer pistas de investigación sobre prácticas que no han sido reflexionadas en todo su significado — como el encierro, el castigo, el ingreso en el hospital, el examen que practica un médico, etc. - , prácticas que no se han examinado con cuidado porque con la fuerza de la costumbre y la rutina, se aceptan como naturales y como si no tuvieran historia.

\section{IV}

No será difícil para el lector observar que no se puede más que terminar indicando que lo que hemos señalado aquí es solo una pequeña invitación a pensar un problema complejo, sobre el que poco se ha reflexionado, particularmente en el caso de los llamados países andinos. Pero es un tema que vale la pena explorar, con estos mismos autores, o con otros, o aun centrándose en corrientes que han sido importantes en las historiografías de América latina en el siglo XIX y XX, como el positivismo, el marxismo, la historia económica y social, o lo que hoy se designa como historia cultural, corrientes que nunca han sido interrogadas desde este punto de vista.

\section{BIBLIOGRAFÍA}

Bloch, Marc. 1993. Apología de la historia o el oficio del historiador. Ciudad de México: Fondo de Cultura Económica.

Borges, Jorge Luis. 2007. Obras completas. Buenos Aires: Emecé. 4 tomos.

Bourdieu, Pierre. 1999. Intelectuales, politica y poder. Buenos Aires: Editorial Universitaria de Buenos Aires.

Bourdieu, Pierre. 2003. El oficio del científico. Ciencia de la ciencia y la objetividad. Curso del Collège de France, 2000-2001. Traducción de Joaquín Jordá. Barcelona: Anagrama.

Boureau, Alain y Daniel S. Milo. 1991. Alter Histoire. Essais d'histoire expérimentale. París: Les Belles Lettres. 
Caianiello, Silva. 2009. «L’enjeu épistémologique de la notion d'époque entre organisme et système au XIXe siècle». Annales. Histoire, Sciences sociales. Número 1: 111-139. https://doi.org/10.1017/S0395264900028596

Canguilhem, Georges. 1970. Études d'histoire de philosophie des sciences. París: J. Vrin. Castelli Gattinara, Enrico. 1998. Les inquiétudes de la raison. Épistémologie et Histoire en France dans l'entre-deux-guerres. París: J. Vrin y Editions de L'École des Hautes Études en Sciences Sociales.

Certau, Michel de. 1987. Histoire et psychanalyse entre science et fiction. París: Gallimard.

Didi-Huberman, Georges. 2008. Ante el tiempo. Historia del arte y anacronismo de las imágenes. Buenos Aires: Adriana Hidalgo Editora.

Foucault, Michel. 1966. El nacimiento de la clínica. Una arqueología de la mirada médica. Ciudad de México: Siglo XXI Editores.

Foucault, Michel. 1967. Historia de la locura en la época clásica. Ciudad de México: Fondo de Cultura Económica.

Foucault, Michel. 1968. Las palabras y las cosas. Una arqueología de las ciencias humanas. Ciudad de México: Fondo de Cultura Económica.

Foucault, Michel. 1976. Vigilar y Castigar. Nacimiento de la prisión. Ciudad de México: Siglo XXI Editores.

Foucault, Michel. 1988. Nietzsche, la genealogía y la historia. Valencia: Pretextos.

Foucault, Michel. 2001a. Dits et écrits I. 1954- 1975. París: Quarto y Gallimard.

Foucault, Michel. 2001b. Dits et écrits II. 1976- 1988. París: Quarto y Gallimard.

Furet, François. 1989. «Antiguo Régimen». En Furet, François y Mona Ozouf (eds). Diccionario de la Revolución francesa. Madrid: Alianza Editorial, 511-521.

Ginzburg, Carlo. 2000. Rapports de force. Histoire, rhétorique, preuve. París: Gallimard y Seuil.

Ginzburg, Carlo. 2010. El hilo y las huellas. Lo verdadero, lo falso y lo ficticio. Buenos Aires: Fondo de Cultura Económica.

Goody, Jack. 1998. El hombre, la escritura y la muerte. Barcelona: Península.

Grafton, Anthony. 2007. What was history? The art of history in early Modern Europe. Cambridge: Cambridge University Press.

Gruzinski, Serge. 1991. La colonización de lo imaginario. Sociedades indígenas y occidentalización en el México español. Siglos XVI-XVIII. Ciudad de México: Fondo de Cultura Económica.

Iggers, George. 2012. La historiografia cientifica del siglo XX: Desde la objetividad cientifica al desafio postmoderno. Santiago: Fondo de Cultura Económica.

Kalifa, Dominique (ed.). 2020. Les noms d'époque. De «Restauration» à «années de plomb». París: Gallimard.

Le Goff, Jacques. 2008. Una larga Edad Media. Barcelona: Paidós. 
Lepetit, Bernard. 1999. Carnet de Croquis. Sur la connaissance historique. París: Albin Michel.

Macherey, Pierre. 2011. De Canguilheim a Foucault: la fuerza de las normas. Buenos Aires: Amorrortu Editores.

Marx, Karl. 2008. Escritos de juventud sobre el derecho. Textos 1837-1847. Barcelona: Anthropos.

Novick, Peter. 1997. Ese noble sueño. La objetividad y la historia profesional norteamericana. Ciudad de México: Instituto de Investigaciones Dr. José Ma. Luis Mora, 2 tomos.

Passeron, Jean-Claude. 2011. El razonamiento sociológico. El espacio comparativo de las pruebas históricas. Madrid: Siglo XXI Editores.

Silva, Renán. 2004. Lugar de dudas. Sobre la práctica del análisis histórico. Bogotá: Universidad de los Andes.

Tosel, André. 2004. «La mise en époque entre nominalisme y réalisme». En Losurdo, Domenico y André Tosel (eds.). Lidée d'époque historique. Fráncfort: Peter Lang, 63-72.

Weber, Max. 1942. Historia económica general. Ciudad de México: Fondo de Cultura Económica.

Fecha de recepción: 31/V/2021 Fecha de aceptación: 1/VII/2021 